MIRÍDIOS NEOTROPICAIS. CCLV: DESCRIÇÕES DE CINCO ESPÉCIES NOVAS E REVALIDAÇÃO DE MONALONION DECORATUM MONTE (HEMIPTERA)

JOSÉ C. M. CARVALHO

\title{
ABSTRACT
}

Five new species of Miridae (Hemiptera) are described: Englemania peruana, from Tingo Maria; Peru; Pycnoderes venezuelanus, from Biscucuy, Venezuela; Euchilochoris bolivarianus, from Chapare, Bolivia, Guacatal in Venezuela and Santa Inez in Ecuador; Neoneella minuscula, from Águas Vermelhas, Minas Gerais, Brazil; and Neofurius quichuanus, from Tingo Maria, Peru. Monalonion decoratum Monte, 1942, is revalidated. Illustration of the habitus and male genitalia of these taxa are included.

No presente trabalho são descritas cinco espécies novas de mirídeos neotropicais e restabelecida a espécie Monalonion decoratum Monte, 1942, descrita de uma fêmea proveniente de Pirenópolis, Estado de Goiás.

Os desenhos que ilustram o texto são de autoria de Paulo Roberto Nascimento, Maria Helena Barreto e Lilia Maria Gomide da Silva, sob supervisão do autor.

\section{Englemania peruana, sp. n.} (Fig. 1)

Caracterizada pela coloração do corpo.

Macho: comprimento 4,0 $\mathrm{mm}$, largura 1,6 mm. Cabeça: comprimento 0,4 $\mathrm{mm}$, largura $1,2 \mathrm{~mm}$, vértice $0,36 \mathrm{~mm}$. Antena: segmento I, comprimento 0,3 $\mathrm{mm}$; II, 0,6 mm; III e IV mutilados: Pronoto: comprimento 0,9 mm, largura na base $1,4 \mathrm{~mm}$. Cúneo: comprimento $0,80 \mathrm{~mm}$, largura na base $0,40 \mathrm{~mm}$ (holótipo).

Coloração geral lutescente com áreas negras; cabeça, pronoto anteriormente e na região dos calos, margem posterior do disco na região mediana e mesoescuto lutescentes; olhos castanhos; segmentos I e II da antena lúteoavermelhados, o II com metade basal negra, escutelo e hemiélitros negros; porção basal do cório, embólio e clavo (mais pronunciado externamente), extremidade apical do cório e do embólio e cúneo lutescentes; membrana fusca; nervuras, margem interna e ápice do cúneo vermelhos; membrana fusca.

Lado interior lutescente; segmento I do rostro, base dos fêmures e abdome avermelhados.

Pronoto e escutelo pontuados, inclusive propleura e lados do mesoesterno, fronte estriada, calos salientes, hemiélitros lisos, cúneo duas vezes mais longo que largo na base, rostro alcançando o segmento genital.

Genitália: não dissecada.

Fêmea: desconhecida.

Holótipo: macho, Peru, Monzon Valley, Tingo Maria, X.21.1954, E. I. Schlinger \& E. R. Ross col., na coleção da Academia de Ciências da Califórnia.

Difere das demais espécies do gênero pela coloração do corpo.

O nome específico é alusivo ao país onde o tipo foi coligido.

Museu Nacional, Rio de Janeiro, RJ. Pesquisador do Conselho Nacional de Desenvolvimento Científico e Tecnológico. 


\section{Monalonion decoratum Monte, 1942}

(Fig. 2)

Monalonion decoratum Monte (1942:143).

Esta espécie foi tratada por mim (Carvalho, 1972:129) como sinônima de Monalonion bahiense Costa Lima, 1938. Atualmente, estudando mais exem. plares pude verificar ser a espécie bem definida. A coloração no exemplar tipo acha-se um pouco mascarada (fêmea). Possui o hemiélitro negro, com o embólio, área comissural do clavo, extrema base do cório e mancha na membrana ocupando quase toda sua extensão pálidos; vértice com duas curtas faixas pretas internamente (uma de cada lado do olho), segmentos II - IV da antena pretos. A cor do fêmur varia, havendo exemplares com fêmur negro mais claro na porção mediana e outros com o fêmur unicolor. Em caso de dúvidua ou ocorrência de um ou outro tipo, a presença das faixas ou manchas negras no vértice ao lado dos olhos é bem característico da espécie, o mesmo podendo ser dito para as manchas claras do hemiélitro.

Exemplares estudados: holótipo, fêmea, Pirenópolis, Goiás, atualmente na coleção Carvalho; 7 exemplares machos e fêmeas: Peru, Pachitea; Peru, Monzon Valley, Tingo Maria, xi.10, 1954, E. I. Schlinger \& E. R. Ross; Yungas, Coroico, Bolívia; Brazil, Manaus, July, 1935, G. V. Vredenburg; Amazonas, Brasil, R. Itacoai, J. C. M. Carvalho col.
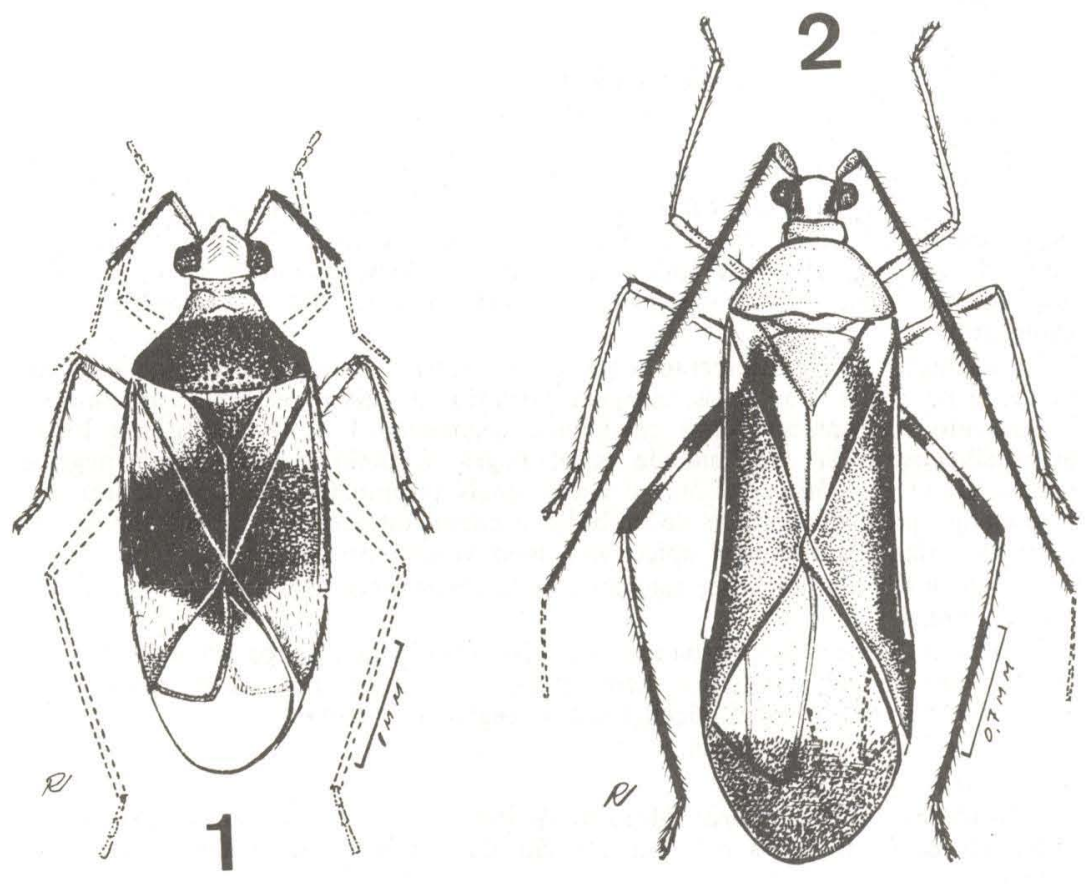

Fig. 1 - Englemania peruana, sp. n., ô, holótipo. Fig. 2 - Monalonion decoratum Monte, ㅇ, holótipo. 


\section{Pycnoderes venezuelanus, sp. n.}

(Fig. 3)

Caracterizada pela coloração geral do corpo e pelo comprimento dos segmentos da antena.

Macho: comprimento 3,6 $\mathrm{mm}$, largura 1,0 $\mathrm{mm}$. Cabeça: comprimento 0,2 $\mathrm{mm}$, largura $0,6 \mathrm{~mm}$, vértice $0,30 \mathrm{~mm}$. Antena: segmento I, comprimento 0,3 $\mathrm{mm}$; II, 0,7 mm; III, 0,7 mm; IV, 0,7 mm. Pronoto: comprimento 0,8 $\mathrm{mm}$, largura na base $1,0 \mathrm{~mm}$. Cúneo: comprimento $0,56 \mathrm{~mm}$, largura na base 0,26 $\mathrm{mm}$ (holótipo).

Coloração geral preta com áreas pálidas; antenas e pernas (exceto o ápice das tíbias anteriores e segmento III dos tarsos) pálidos; embólio (exceto extrema margem externa), mancha subapical externa no exocório e cúneo (exceto extremidade apical e extrema margem externa) pálido-amarelados; mem-

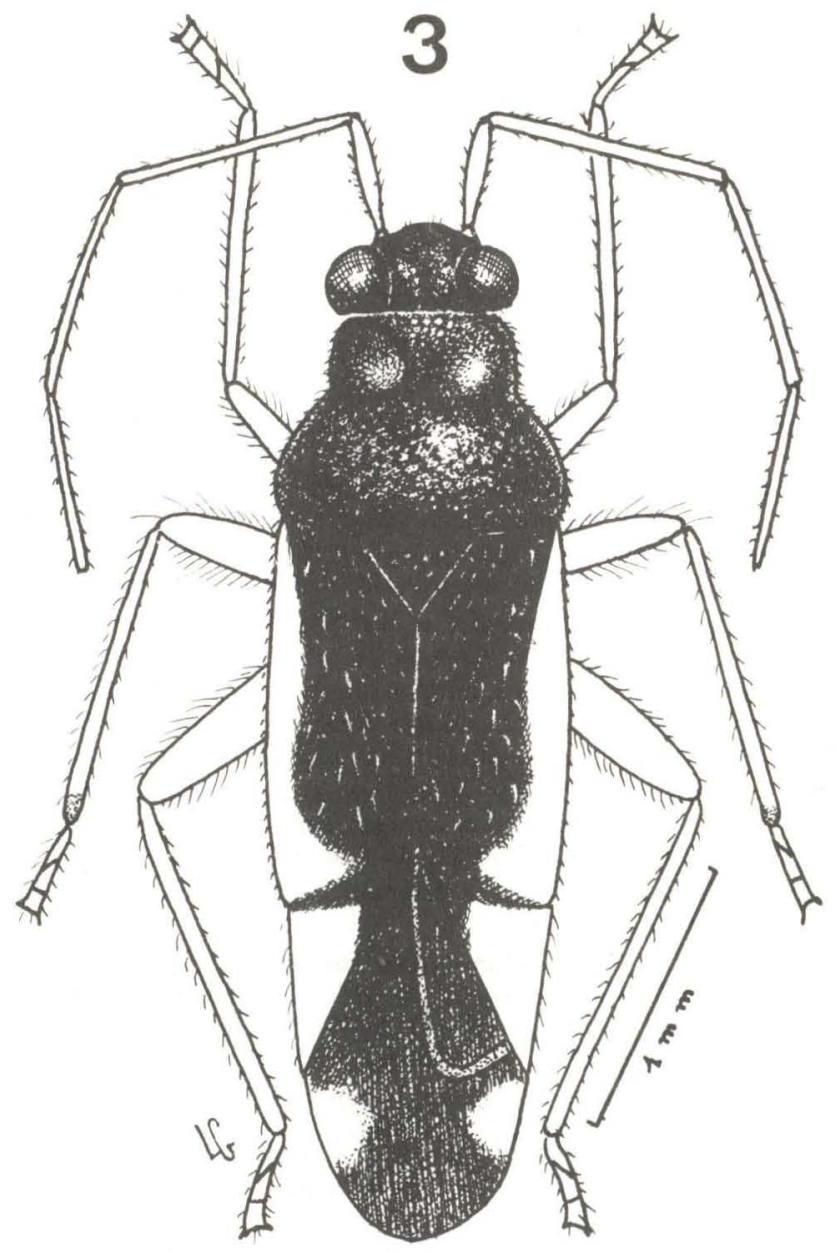

Fig. 3 - Psycnoderes venezuelanus, sp. n., ô, holótipo. 
brana fusco-escura com mancha pálida além do ápice do cúneo. Clavo e cório com pruinosidade prateada.

Lado inferior preto, brilhante; parte anterior da cabeça, vista de lado, um pouco mais clara.

Rostro alcançando o meio do mesoesterno; pronoto, escutelo e meoesterno pontuados; clípeo saliente, arredondado na frente; nervura costal côncava na região mediana.

Genitália: não dissecada por tratar-se de exemplar único.

Fêmea: desconhecida.

Holótipo: macho, Venezuela, est. Portuguesa, 15.ix.1957, Borys Malkin, $7 \mathrm{~km} \mathrm{n}$ Biscucuy, Bonoco-Biscucuy Road, elev. $600 \mathrm{~m}$, na coleção do Museu Nacional de História Natural dos Estados Unidos da América (USNMNH), Washington, D.C.

Difere das demais espécies do gênero para coloração do hemiélitro e pelo comprimento relativo dos segmentos da antena.

O nome específico é alusivo ao país de origem da espécie.

Euchilocoris bolivarianus, sp. n.

(Figs. 4-7)

Caracterizada pela coloração do pronoto.

Fêmea: comprimento $11,2 \mathrm{~mm}$, largura $3,8 \mathrm{~mm}$. Cabeça: comprimento $0,8 \mathrm{~mm}$, largura $1,7 \mathrm{~mm}$, vértice $0,68 \mathrm{~mm}$. Antena: segmento I, comprimento $1,0 \mathrm{~mm}$; II, $3,2 \mathrm{~mm}$; III, 1,4 mm; IV, 1,0 mm. Pronoto: comprimento 1,6 mm, largura na base $3,5 \mathrm{~mm}$. Cúneo: comprimento $1,72 \mathrm{~mm}$, largura na base 1,04 $\mathrm{mm}$ (holótipo).

Coloração geral castanha com áreas pálido-amareladas; margem posterior interna dos olhos e lados da cabeça pálidos; duas manchas arredondadas no disco atrás dos calos branco-leitosas; margem posterior do disco finamente, ápice do escutelo, lados da comissura corial e ápice do clavo, fratura cuneal do lado do cório e embólio, mancha semicircular na região do ângulo basal interno e ápice do cúneo pálido-amarelado; membrana fusca.

Lado inferior pálido-amarelado a alaranjado; segmentos abdominais do III ao VII com manchas negras; ovipositor preto.

Espécie de grande porte; pronoto brilhante e fortemente pontuado; fronte estriada; hemiélitro com pubescência lanosa muito curta e de tonalidade prateada; escutelo proeminente na porção mediana.

Macho: semelhante à fêmea em coloração e aspecto geral. No exemplar estudado as tíbias II e III são castanhas, com anel subasal pálido e ápice castanho; pigóforo preto. A coloração do lado superior é idêntica à da fêmea.

Em dois exemplares (macho e fêmea) a mancha branco-leitosa atrás dos calos são de tamanho reduzido.

Genitália: pênis (Fig. 5) com vésica formada por lobos membranosos e um campo de espinhos esclerosados ao lado do gonóporo secundário. Parâmero esquerdo (Fig. 6) curvo, lobo basal bem desenvolvido, cerdas dorsais curtas. Parâmero direito (Fig. 7) simples, irregular.

Holótipo: fêmea, Limbo, Bolívia, Chapare, $2.000 \mathrm{~m}$. xi.79, Prosen, na coleção do USNMNH. Parátipos: macho, mesmas indicações que o tipo; fêmea, Venezuela, D. F. Hacienda El Limon, Guacatal, 1.500 m, $10^{\circ} 27^{\prime} \mathrm{N}$ 67016’O, 22.vii.1971, L. J. Joly T; fêmea, Santa Inez, Ecuador, R. Haensch R., na coleção do autor.

Difere das demais espécies do gênero pela coloração do pronoto e pela morfologia da genitália do macho.

O nome específico é alusivo aos países ditos bolivarianos, dos quais em pelo menos três a espécie já foi encontrada. 


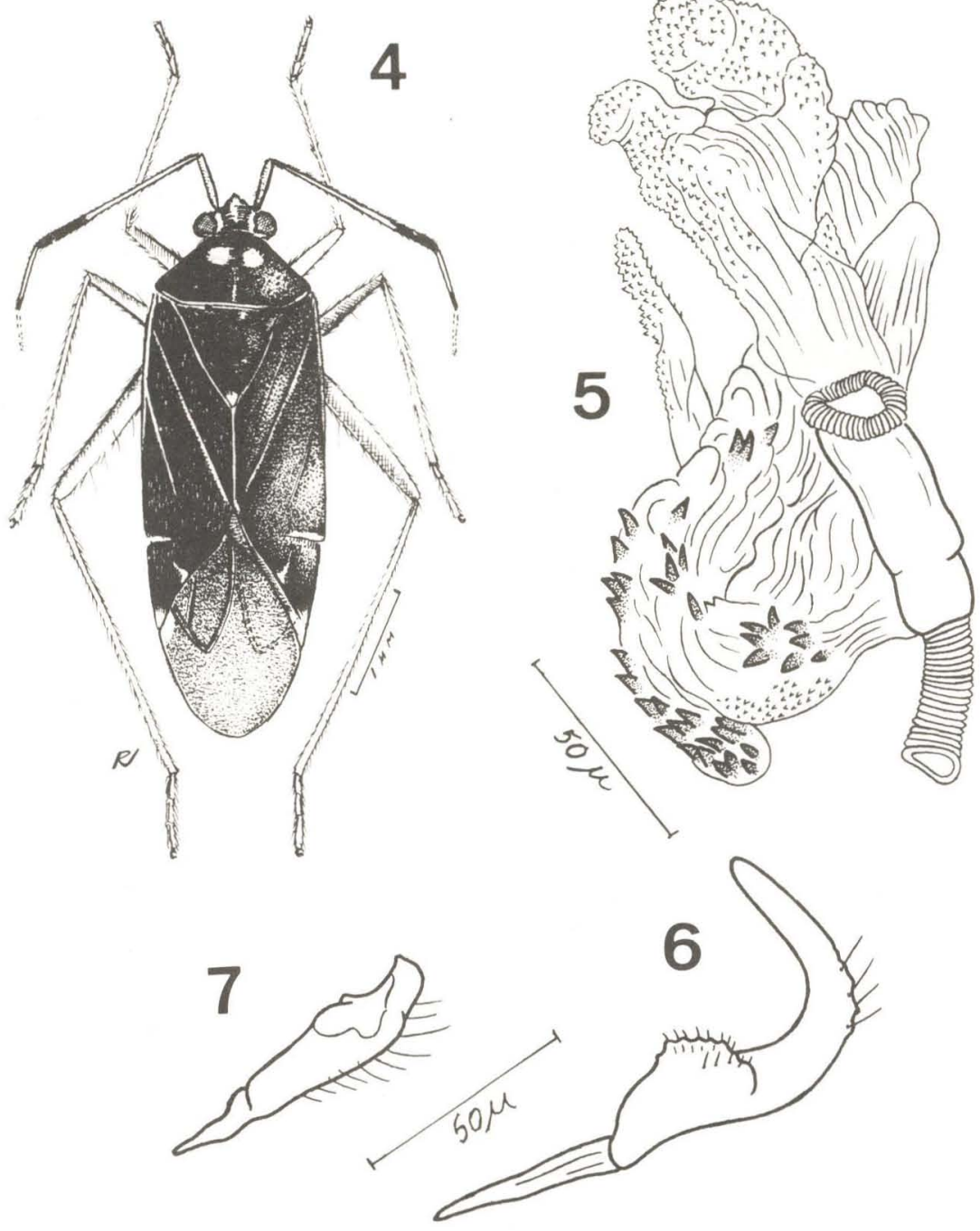

Euchilochoris bolivarianus, sp. n. Fig. 4 - , holótipo; Fig. 5 - Pênis; Fig. 6 - Parâmero esquerdo; Fig. 7 - Parâmero direito.

\section{Neoneella minuscula, $\mathrm{sp} . \mathrm{n}$.}

(Figs. 8-11)

Caracterizada pela morfologia da antena e da genitália do macho.

Macho: comprimento $6,0 \mathrm{~mm}$, largura $3,2 \mathrm{~mm}$. Cabeça: comprimento 0,3 $\mathrm{mm}$, largura $1,3 \mathrm{~mm}$, vértice $0,72 \mathrm{~mm}$. Antena: segmento I, comprimento 0,4 $\mathrm{mm}$; II, $1,8 \mathrm{~mm}$; III, 0,8 mm; IV, 0,6 mm. Pronoto: comprimento $0,8 \mathrm{~mm}$, 

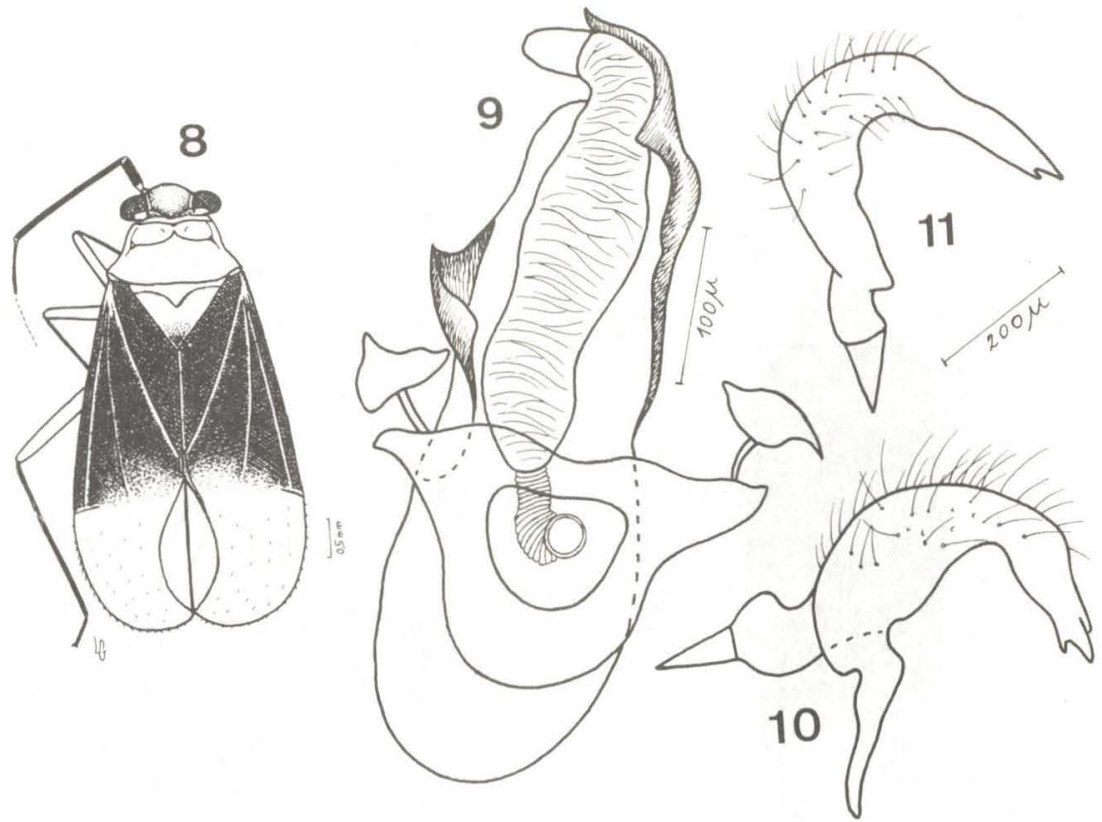

Neoneella minuscula, sp. n. Fig. 8 - ô, holótipo; Fig. 9 - Pênis; Fig. 10 Parâmero esquerdo; Fig. 11 - Parâmero direito.

largura na base $1,6 \mathrm{~mm}$. Cúneo: comprimento $1,4 \mathrm{~mm}$ (da base em linha transversal até o ápice), largura na base $1,2 \mathrm{~mm}$ (holótipo).

Coloração geral castanha com áreas lúteo-avermelhadas; cabeça, pronoto, escutelo e extrema base do cório e embólio lúteo-avermelhados, olhos castanhos, pedúnculo antenal e base do segmento III da antena pálidos, cúneo pálido-amarelado, membrana fusca.

Lado inferior lúteo-avermelhado, tíbias pretas (exceto no extremo ápice), tarsos lutescentes, segmento III negro.

Corpo finamente pontuado no pronoto e rugoso no hemiélitro, olhos pedunculados, escutelo excavado na base, cúneo muito largo e longo, curvo externamente, alcançando a extremidade apical do hemiélitro, circundando a membrana cuja aréola é alongada e única, pêlos do pronoto lutescentes, negros no hemiélitro e claros na margem externa do cúneo, rostro alcançando as coxas medianas, antena II curva (retorcida no meio).

Genitália: pênis (Fig. 9) do tipo Bryocorini, vésica membranosa, sem espículos esclerosados. Parâmero esquerdo (Fig. 10) com duas ramificações, o lobo subasal afilado, como mostra a ilustração. Parâmero direito (Fig. 11) curvo, alongado, bifurcado na extremidade apical.

Fêmea: desconhecida.

Holótipo: macho, Águas Vermelhas, Minas Gerais, Brasil, xii.1983, Moacyr Alvarenga col., na coleção do Museu Nacional, Rio de Janeiro. Parátipo: um macho, mesmas indicações que o tipo, na coleção do autor.

Difere das demais espécies do gênero pelo seu pequeno porte e pela morfologia da genitália do macho.

O nome específico é alusivo ao seu pequeno tamanho. 
Neofurius quichuanus, sp. $\mathrm{n}$.

(Figs. 12-13)

Caracterizada pela coloração geral do corpo e pela morfologia da genitália do macho.

Macho: comprimento 4,2 $\mathrm{mm}$, largura $1,8 \mathrm{~mm}$. Cabeça: comprimento $0,2 \mathrm{~mm}$, largura $0,7 \mathrm{~mm}$, vértice $0,40 \mathrm{~mm}$. Antena: segmento I, comprimento 0,5 mm; II, 0,8 mm; III, 0,5 mm; IV, 0,4 mm. Pronoto: comprimento 0,8 $\mathrm{mm}$, largura na base $1,3 \mathrm{~mm}$. Cúneo: comprimento $0,80 \mathrm{~mm}$, largura na base $0,60 \mathrm{~mm}$ (holótipo).

Coloração geral lutescente-avermelhado com áreas fuscas a negras; cabeça, pronoto e escutelo lúteo-avermelhados (região mediana posterior do disco e escutelo vermelhos), olhos castanhos, antena negra com extrema base do segmento I e pedúnculo antenal pálidos; hemiélitro lutescente com faixa mediana longitudinal no clavo e endocório castanho-avermelhada (mais intensamente no meio do clavo); membrana fuscá, pálida além do ápice do cúneo.
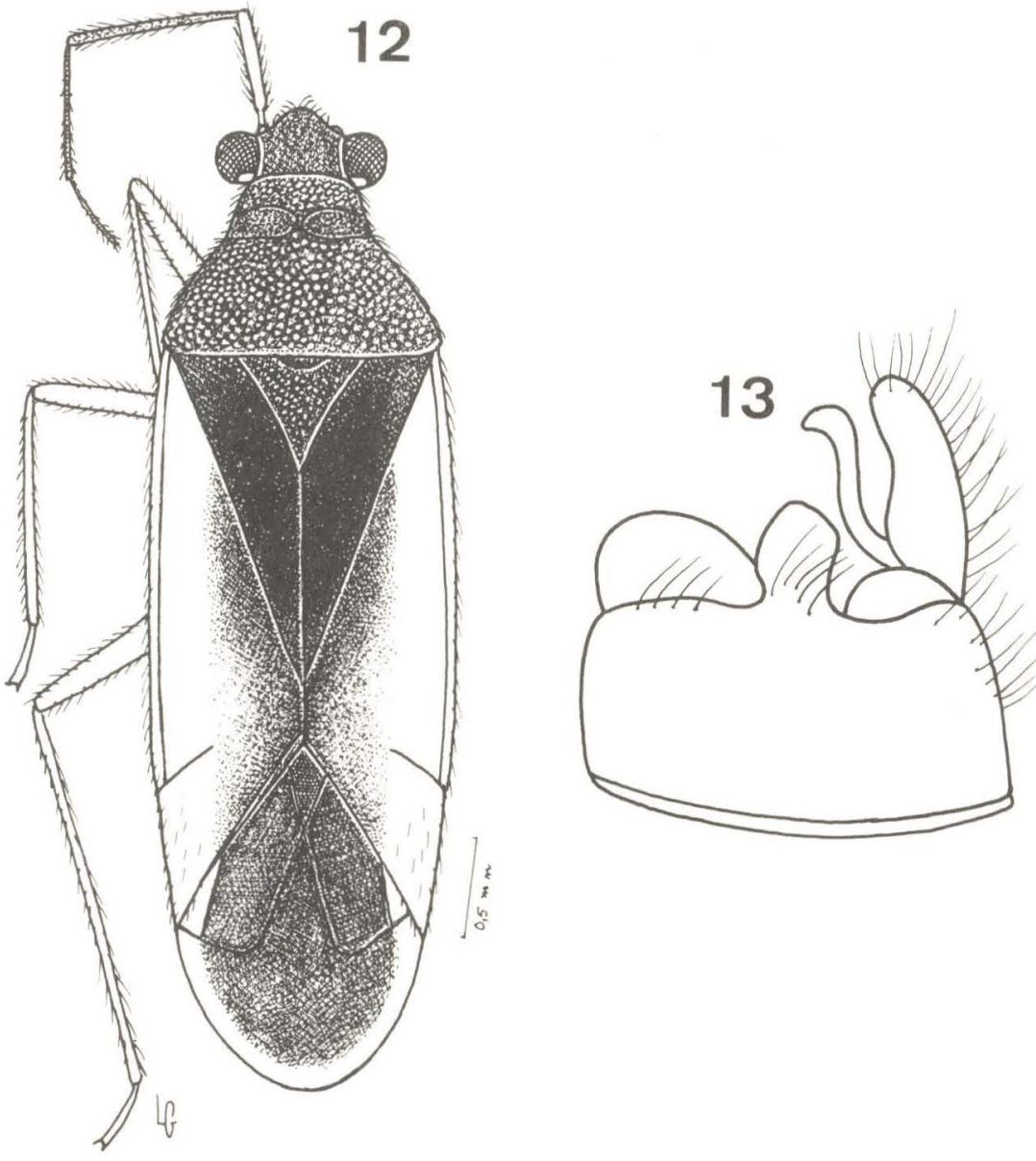

Fig. 12 - Neofurius quichuanus, sp. n., ô, holótipo. Fig. 13 - Parâmero esquerdo. 
Lado inferior e pernas lutescentes, epifaringe e abdome avermelhados.

Corpo com pilosidade densa, fina e erecta (inclusive nos fêmures e tíbias), comprimento dos pêlos na antena igual ou maior que a grossura dos segmentos, rostro alcançando as coxas medianas.

Genitália: não dissecada por se tratar de exemplar único. Parâmero esquerdo visto externamente bipartido, os dois ramos de comprimento igual.

Fêmea: desconhecida.

Holótipo: macho, Peru, Monzon Valley, Tingo Maria, x.26.1954, E. I. Schlinger \& E. S. Ross col., na coleção da Academia de Ciências da Califórnia, San Francisco.

Difere das demais espécies do gênero pela coloração do corpo e pela morfologia do parâmero esquerdo.

O nome específico é alusivo aos habitantes primitivos de uma larga faixa do território abrangido pela cadeia dos Andes.

\section{REFERENCIAS}

Carvalho, J. C. M., 1972. Mirídeos neotropicais. CXLVI: Gênero Monalonion H.-S. (Hemiptera). An. Acad. bras. Ci. 44(1):

Monte, O., 1942. Uma nova espécie do gênero Monalonion Herrich-Schaeffer. Papéis avulsos Zool., S Paulo 2(10): 143. 